\title{
FINANÇAS COMPORTAMENTAIS: análise do perfil comportamental do investidor e do propenso investidor
}

\section{1- Wesley Vieira Silva \\ Pontifícia Universidade Católica do Paraná - PUC/PR wesley.vieira@pucpr.br}

\section{3- Sandra Maria da Silva \\ Pontifícia Universidade Católica do Paraná - PUC/PR sms.amaral@uol.com.br}

\author{
2- Jansen Maia Del Corso \\ Pontifícia Universidade Católica do Paraná - PUC/PR \\ del.corso@pucpr.br
}

\author{
4- Eliane de Oliveira \\ Pontifícia Universidade Católica do Paraná - PUC/PR \\ elianedeoliveira@aol.com
}

\section{RESUMO}

Finanças comportamentais, também conhecidas por Economia Comportamental, representam um novo campo na teoria financeira que busca incorporar os aspectos psicológicos dos indivíduos no processo de avaliação e precificação de ativos financeiros. Este novo campo do estudo de Finanças tem como objetivos a revisão e o aperfeiçoamento do modelo econômicofinanceiro atual, pela incorporação de evidências sobre a irracionalidade do investidor. A fim de obter maiores informações sobre o perfil comportamental de investidores e propensos investidores, realizou-se uma pesquisa descritiva de natureza quantitativa baseada na aplicação de um questionário estruturado composto de 20 perguntas direcionadas a 164 discentes e 33 docentes do curso de Administração da Pontifícia Universidade Católica do Paraná. Os resultados auferidos por meio de técnicas estatísticas multivariada como a análise de cluster e análise de discriminante, tornaram-se possível identificar cinco grupos com características distintas de importância relevante para o estudo realizado. Verifica-se ainda que grande parcela dos respondentes afirmou não possuir conhecimentos acerca deste mercado, bem como muitos ainda se classificando como aprendizes.

Palavras-Chave

Finanças comportamentais, Aversão à perda, Precificação, Análise de Cluster, Análise de discriminante.

\section{ABSTRACT}

Behavioral finance is also known for behavioral economy and it represents a new line in the financial theory that is searches to incorporate the psychological aspects individuals in the evaluation process and pricing of financial assets. This new study line of finances has as objective the revision and the improvement of the current economic financial model for the incorporation of evidences on the irrationality of the investor. In order to get greater information on the behavioral profile of investors and keens investor a exploratory research and with quantitative approach was produced with base on the application of composed questionnaire of 20 directed questions for 164 students and 33 professors of course of management of the Pontifícia Universidade Católica do Paraná. The results were obtained through multivariate statistical techniques as cluster analysis and discriminant analysis. On the analysis five groups with distinct characteristics of importance for the study. A lot of answering assert doesn't hold knowledge about financial market.

\section{Keywords}

Behavioral Finance, Last Aversion, Pricing, Custer Analysis, Discriminant Analysis. 


\section{Introdução}

As finanças comportamentais constituem um novo campo de estudos, que se contrapõem ao pressuposto de racionalidade dos tomadores de decisão adotado pelas finanças Tradicionais. Conceitos provindos de ciências como economia, finanças, e psicologia cognitiva oferecem subsídios às finanças comportamentais com o objetivo de construir um modelo mais detalhado do comportamento humano nos mercados financeiros; calcado basicamente na idéia de que os agentes econômicos estão sujeitos a vieses comportamentais que muitas vezes, os afastam de uma decisão centrada na racionalidade.

Atualmente, as finanças comportamentais são um dos ramos mais polêmicos do estudo de finanças, reforçadas ainda pela atual turbulência do mercado financeiro internacional. As mudanças qualitativas no Modelo Moderno de Finanças proposto pelos defensores das finanças comportamentais são muito substanciais, uma vez que dizem respeito ao elemento mais importante do mercado financeiro: o investidor.

O conceito de aversão à perda é considerado um dos pilares das finanças comportamentais. Este modelo comportamental diz que o investidor pondera tanto os ganhos quanto as perdas, mas não dá a ambos o mesmo valor psicológico. Para Kahneman e Tverski (1979) os investidores sentem muito mais a dor da perda do que o prazer obtido com um ganho equivalente.

Para Baker e Nofsinger (2002), o melhor entendimento e delimitação para as falhas cognitivas individuais permitiriam aos investidores melhorarem sua capacidade decisória, evitando com isso, as falhas no processo de alocação de ativos.

Este trabalho tem como objetivos centrais: trazer à tona esse novo assunto tão discutido internacionalmente, mas que ainda possui uma baixa repercussão no Brasil; bem como, apresentar os resultados da pesquisa exploratória de natureza quantitativa, a qual se baseou na utilização de técnicas estatísticas multivariadas, visando obter maior compreensão acerca do perfil comportamental do investidor e do propenso investidor.

O presente trabalho encontra-se estruturado em cinco seções que podem ser descritas da seguinte forma: a primeira refere-se a parte introdutória; a segunda trata do referencial teórico-empírico acerca da teoria de finanças comportamentais; a terceira refere-se a metodologia utilizada nesta pesquisa; a quarta trata da apresentação e análise dos dados coletados e a quinta refere-se as considerações finais e recomendações para trabalhos futuros.

\section{Referencial Teórico-Empírico}

Os estudos relacionados às finanças comportamentais (behavioral finance) foram incorporados ao contexto de finanças nas últimas décadas em decorrência das anomalias irracionais produzidas pelas crises financeiras que não conseguiram ser explicadas pelo Modelo Moderno de Finanças. Haugen (1999 p. 153) alerta que o modelo de fator de retorno esperado, centrado em um mercado de ações eficiente e racional, apenas consegue explicar, em média, 10\% das diferenças de retorno nas ações.

Os fundamentos das finanças comportamentais encontram-se centrados decisivamente nos trabalhos de dois psicólogos e docentes israelenses: Amos Tversky e Daniel Kahneman. Mesmo não sendo economista, Daniel Kahneman foi congratulado com o Prêmio Nobel de Economia no ano de 2002.

Os trabalhos destes dois psicólogos compreendendo os anos de 1974 e 1979 representam a base teórica para a análise do comportamento de investidores, teve um papel fundamental para o início do desenvolvimento das finanças comportamentais.

No entanto, este novo campo de estudo apenas ganhou força e sustentabilidade com os trabalhos realizados pelo economista Richard Thaler, o qual se opôs na vanguarda de um grupo de economistas acadêmicos reagindo à falhas do modelo racional, inaugurando o novo campo de estudos das finanças comportamentais (BERNSTEIN, 1997).

Segundo Thaler (1999) torna-se possível enriquecer o entendimento do funcionamento do mercado financeiro adicionando a compreensão do elemento humano. Seguindo a mesma linha de raciocínio do referido autor, no mercado existem duas classes distintas de investidores: os totalmente racionais e os quase-racionais. Os quase-racionais, por exemplo, tentam tomar boas decisões de investimento, mas cometem de maneira comum erros previsíveis. A maior parte destes erros, segundo o autor, resulta de falhas no processo racional devido a interferências de motivações intrínsecas dos seres humanos. Descobrir, estudar e demonstrar aos investidores quando estes motivos os podem prejudicar é o principal objetivo das finanças comportamentais. 
Quanto aos conceitos de finanças comportamentais, embora existam diversas definições, verifica-se uma convergência entre elas. Lintner (1998 apud Marcon et al., 2005, p. 2), por exemplo, define finanças comportamentais como os estudos por meio dos quais os investidores interpretam e agem frente às informações para decidir sobre investimentos.

Grande parte dos estudos sobre o comportamento individual de disposição ou aversão ao risco e sua mensuração leva em conta fatores que podem influenciá-lo. De acordo com Lampenius e Zickar (2005, p. 131), em geral, o foco recai sobre características como gênero, idade, estado civil, profissão, renda, escolaridade e conhecimento sobre finanças.

Uma pesquisa conduzida por Grable (2000, p. 626) buscou determinar os fatores socioeconômicos com maior significância estatística para diferenciar os indivíduos de acordo com os seus níveis de tolerância ao risco. Entretanto, o modelo desenvolvido para testar a hipótese foi capaz de explicar apenas aproximadamente $22 \%$ da tolerância individual ao risco financeiro. Os resultados de Grable (2000, p. 626) em muito se aproximaram dos obtidos por Carducci e Wong (1998, p. 358-359), onde indicam que indivíduos com maior grau de escolaridade, maior conhecimento em finanças, maiores proventos e que ocupam postos profissionais mais elevados são mais tolerantes ao risco do que os demais.

Grable (2000, p. 627) afirma que boa parte do sucesso em investimentos financeiros parece ser explicada pela combinação de indicadores socioeconômicos e por características da personalidade dos indivíduos.

Já Thaler (1999) define finanças comportamentais como simples finanças de cabeça aberta, salientando que algumas vezes para achar a solução de um problema financeiro empírico é necessário aceitar a possibilidade que alguns dos agentes na economia se comportem, em alguns momentos, de forma não completamente racional.

Olsen (1998 apud LIMA, 2003, p. 4) sustenta que as finanças comportamentais não tentam definir o comportamento racional como sendo racional ou irracional, mas sim entender e predizer os processos de decisão psicológicos que implicam na sistemática dos mercados financeiros.

Apesar de até o momento não existir nenhuma teoria unificada de finanças comportamentais, a maioria das pesquisas neste campo tem-se concentrado no estudo das ilusões cognitivas, em seus reflexos no comportamento dos decisores e nas formas como estas ilusões podem interferir no mercado financeiro.

Há estudos que indicam que a disposição ou aversão do investidor em relação ao risco financeiro não é um atributo uniforme, nem tampouco pode ser generalizado para outras atividades. Por exemplo, uma pessoa pode demonstrar uma elevada disposição ao risco (ou a sensação de disposição ao risco) praticando um esporte, mas ser um investidor conservador. Pesquisas demonstram que medidas gerais de disposição ao risco ou sensação de disposição não predizem bem a disposição do indivíduo ao risco financeiro (LAMPENIUS; ZICKAR, 2005, p. 130).

Existe uma tensão persistente entre aqueles que afirmam que as melhores decisões se baseiam na quantificação e nos números, e são determinadas pelos padrões do passado, e aqueles que baseiam suas decisões em graus de crença mais subjetivos sobre o futuro incerto (BERNSTEIN, 1997). Ainda que essa controvérsia não tenha sido solucionada, Shiller (2000 apud HALFELD; TORRES, 2001, p. 65) aponta que grande parte do pensamento humano que resulta em ação não se baseia em dados quantitativos, mas sim em histórias e justificativas.

Uma das hipóteses principais do Modelo Moderno de Finanças é a idéia de que o homem é um ser perfeitamente racional (homo economicus) que, no processo de tomada de decisão, é capaz de analisar todas as informações disponíveis e considerar todas as hipóteses para solução do problema. As finanças comportamentais surgem como uma tentativa de aperfeiçoar o Modelo Moderno de Finanças por meio da incorporação ao modelo de estudos sobre o comportamento e a irracionalidade do homem.

Boa parte das questões levantadas até aqui levam em conta decisões financeiras é fundamentada nas discussões sobre a racionalidade limitada do indivíduo, segundo Simon (1976, p. 103). Simon questiona a chamada racionalidade substantiva, pela qual um indivíduo tem a capacidade irrestrita de atingir seus objetivos da melhora maneira possível, sempre maximizando os resultados. Ao contrário, as situações reais são percebidas de modo diferente pelos indivíduos, o que poderá influenciar suas inferências e decisões. Há também inferências elaboradas a partir das experiências anteriores dos indivíduos.

O homem das finanças comportamentais não é totalmente racional; é um homem simplesmente normal. Essa normalidade implica um homem que age, freqüentemente, de maneira irracional, que 
tem suas decisões influenciadas por emoções e erros cognitivos, fazendo com que ele entenda um mesmo problema de formas diferentes, dependendo da maneira como é analisado.

O campo de estudos das finanças comportamentais é justamente a identificação de como essas emoções e os erros cognitivos podem influenciar o processo de decisão de investidores e como esses padrões de comportamento podem determinar mudanças no mercado. $O$ grande desafio para os pesquisadores está em provar que tais anomalias de comportamento são realmente previsíveis e podem modificar o mercado de forma definida.

Diversos padrões de comportamento (os mais citados são a aversão à perda, a autoconfiança excessiva, os exageros quanto ao otimismo e ao pessimismo) foram identificados por diferentes pesquisadores sem que se conseguisse a formulação de um modelo que englobem todos eles. Os modelos sugeridos até o momento se limitam a explicar uma anomalia em particular e falham na tentativa de explicar outras (FAMA; FRENCH, 1988), dando argumentos aos opositores das finanças comportamentais.

Como afirmou Thaler (1999), talvez em um futuro próximo falar de finanças comportamentais possa parecer redundância, já que as finanças devem incorporar em seus modelos os avanços na compreensão da forma como os investidores realmente tomam decisões. Talvez as finanças comportamentais, ao forçar os teóricos das Finanças Modernas a reverem os pressupostos da racionalidade e eficiência dos mercados, possam favorecer uma integração com as Finanças Tradicionais e, assim, caminhar no sentido de uma teoria unificada em finanças.

\section{- Aversão à perda}

O conceito de aversão à perda é considerado um dos pilares das finanças comportamentais. Esse modelo comportamental diz que o investidor pondera tanto os ganhos quanto as perdas, mas não dá a ambos o mesmo valor psicológico. Para Kahneman e Tverski (1979) os investidores sentem muito mais a dor da perda do que o prazer obtido com um ganho equivalente.

Esta teoria contraria o conceito microeconômico conhecido como Teoria da Utilidade, e tem como curva de utilidade o comportamento expressado a partir da Figura 1(a), o qual supõe que o investidor avalia o risco de um investimento de acordo com a mudança que ele proporciona em seu nível de riqueza; esse preceito é parte integrante do Modelo Moderno de Finanças, e trabalha com o conceito de que o investidor é perfeitamente racional.

O investidor, segundo as finanças comportamentais, avalia o risco de um investimento com base em um ponto de referência a partir do qual, mede os ganhos e perdas. Kahneman e Tverski (1979) sugerem uma nova curva de riscoutilidade que possui um comportamento tal como encontra-se expressado na Figura 1(b), que seria justamente a representação da maneira comportamental de se avaliar o risco de um investimento. Essa curva tem como principais características a descontinuidade na origem (determinando a origem do sistema cartesiano como o ponto de referência na avaliação dos riscos de um investimento) e o declínio da curva após esse ponto (representando que os investidores sentem mais dor a perda do que o prazer do ganho).
Figura 1(a): Curva de Utilidade Valor

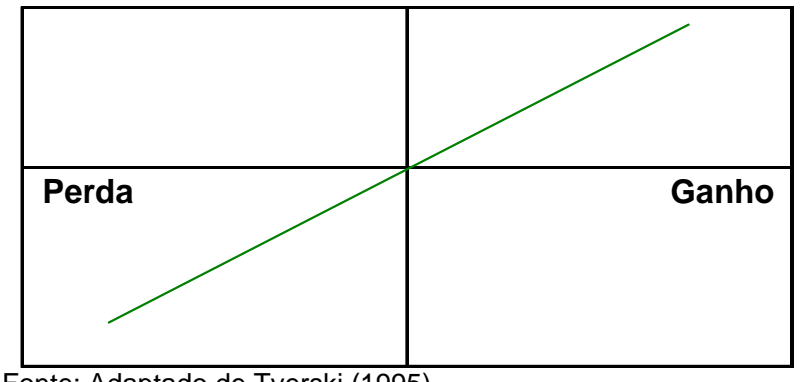

Fonte: Adaptado de Tverski (1995)
Figura 1(b): Curva de Risco-Utilidade

Valor

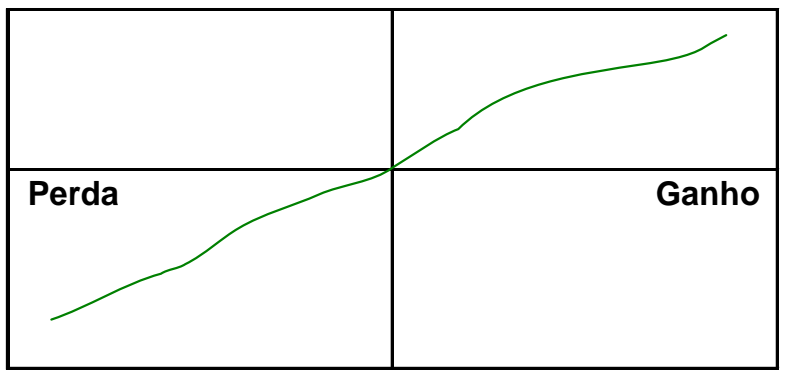

Existe, ainda, outra característica do comportamento humano relacionada à aversão à perda que é visto pelos estudiosos das finanças comportamentais como: 0 medo do arrependimento. Segundo Halfeld e Torres (2001), é muito doloroso para os investidores assumirem seus erros, fazendo com que eles tenham um comportamento que não proporciona o maior lucro 
possível em uma operação somente para evitar reportar uma perda, o que, novamente, contradiz a Teoria da Utilidade.

Halfeld e Torres (2001) exemplificam indivíduos que evitam vender papéis por um preço inferior ao da compra, mantendo-os em sua carteira de investimentos por longos intervalos de tempo e comprometendo sua liquidez conscientemente, deixando de realizar melhores opções de negócios nesse período devido ao medo de arrependimento. A vergonha ou constrangimento de informar de que se realizou um mau investimento acaba por fazer com que alguns participantes do mercado façam opções somente por ações de grandes empresas ou assumam posições sempre com a maioria do mercado. Isso parece explicar, em parte, o grande medo que uma parcela considerável da população tem de aplicar em Bolsa de Valores. O sistema de exibir as cotações diariamente, resultado da elevada liquidez de ativos, demonstra de forma muito direta quando o investidor acertou e quando cometeu um erro.

O medo de sentir arrependimento pode explicar por que tantos potenciais investidores preferem oferecer a gestão de seu patrimônio a um terceiro, mesmo sem exigir uma comprovação clara de sua capacidade. Isto parece acontecer porque, em caso de erro, os investidores podem atribuir culpa a outro. Procurar um culpado pelos erros cometidos parece ser uma constante para muitos investidores, inclusive alguns considerados experientes.

Os investidores são afetados pelo efeito disposição. Tal efeito afeta particularmente, investidores muito avessos a perdas, pois eles supõem ser extremamente relutantes em realizar perdas. O efeito disposição faz com que eles se tornem muito mais propensos a vender suas ações com boa performance recente e a manter as ações com performances medíocres (HALFELD; TORRES, 2001, p. 68).

Algumas vezes, o investidor "esquece" uma ação que caiu muito de preço e vende muito rápido todas as ações com boa performance (BARBER; ODEAN, 2000, apud MACEDO, 2005, p. 69). Isso faz com que alguns investidores tenham carteiras que são verdadeiras amostras de empresas que não deram certo, ou que se denomina no mercado financeiro de "jaula de micos". E porque fazem isto? Basicamente visando sentir prazer ou se sentir inteligente ao vender um investimento com lucro e não ter que vender um investimento no qual tiveram prejuízos, pois, tal como afirmou Tversky (1995), os estímulos negativos são muito mais potentes nos humanos do que os positivos.
Segundo Lima (2003), a aversão a perdas e o conseqüente efeito disposição estão associados a um estado da mente do indivíduo que tem dificuldade para reconhecer seus erros, ou, em outras palavras, os indivíduos costumam se achar muito mais expertos do que realmente são. A idéia básica é de que a penalidade associada a uma determinada perda é muito maior que a recompensa mental de um ganho do mesmo tamanho.

Dhar e Zhu (2006) observaram a presença do efeito disposição numa parcela ainda maior dos investidores: aproximadamente $80,3 \%$. Segundo os autores, apesar do número de investidores que exibiram efeito disposição ser inferior ao reportado em outras pesquisas, o percentual de respondentes exibindo o viés, aproximadamente $40 \%$, sugere a presença do efeito disposição em uma parcela significativa dos investidores, levando, portanto, à rejeição da hipótese nula de que os investidores não apresentam evidências do efeito disposição. As análises obtidas nesta pesquisa para o mercado americano não evidenciam relações claras entre o efeito disposição e as características dos investidores (com base em regressões não reportadas, mas, cujos resultados foram disponibilizados pelos autores).

Muitos investidores costumam vender muito cedo títulos em alta para poder realizar um ganho certo e costumam manter títulos com queda significativa na esperança de uma reversão da situação para não realizar a perda (MACEDO, 2005 , p. 70). Note que se o preço caiu, eles efetivamente já perderam, pois poderiam ter vendido com o preço anterior maior e comprado com o preço atual menor. Porém, como eles não venderam, mentalmente, não consideram que perderam.

Não apenas pequenos e inexperientes investidores estão propensos ao efeito disposição, pois alguns estudos demonstram que mesmo investidores institucionais como, por exemplo, gestores de fundos de pensão e de fundos de investimento, são comumente afetados pelo efeito disposição.

\section{- Autoconfiança Excessiva}

O excesso de confiança representa uma característica presente na grande maioria da população mundial. Tversky e Kahneman (1981) acharam evidências de serem os investidores exageradamente otimistas sobre as suas decisões de investimentos, superestimando as chances de sucesso e seus conhecimentos financeiros. 
Um estudo desenvolvido por Odean (1998, p. 1797), mostra claramente que a maioria dos investidores, ao contrário do que eles mesmos acreditam, não consegue vencer o mercado. Analisando mais de 10 mil negócios de investimento no mercado financeiro norteamericano, conclui que os papéis vendidos tiveram um desempenho $3,4 \%$ maior do que os papéis comprados nessas negociações. Assim, o autor chegou à seguinte conclusão: "os investidores individuais demonstram preferência significativa em vender ações vencedoras e manter ações perdedoras, exceto em dezembro, quando as vendas motivadas por razões fiscais (abatimento do imposto de renda) prevalecem".

A autoconfiança excessiva desencadeia nos investidores uma convicção de que suas informações são melhores e mais confiáveis que as dos outros investidores que atuam no mesmo mercado. Em negociações comerciais, comumente, cada parte envolvida dispõe de informações distintas e muitas vezes contraditórias. No entanto, reflexões e análises mais apuradas são postas em segundo plano, prevalecendo a confiança exagerada nas suas habilidades e informações disponíveis. Os resultados obtidos se materializam na tendência a realizar um volume de negócios excessivos, com uma dosagem acentuada de risco.

\section{Metodologia da Pesquisa}

\subsection{Caracterização da Pesquisa}

A pesquisa realizada caracteriza-se como um estudo de natureza exploratório, com amostragem por conveniência e adesão, com o objetivo de conhecer melhor o perfil da amostra pesquisada. Tal pesquisa pode ainda ser caracteriza como exploratória, uma vez que procuram levantar características inéditas que possibilitam estabelecer prioridades para futuros estudos, desenvolvendo hipóteses e proposições que poderão redundar em pesquisas complementares. Segundo Churchill Junior (1998), o objetivo desse tipo de pesquisa é ganhar insights e idéias, sendo caracterizadas por sua flexibilidade em relação aos métodos usados e ao levantamento das informações.

\subsection{Coleta dos Dados}

A amostra usada neste trabalho é composta por 164 discentes regularmente matriculados e 33 docentes vinculados ao curso de graduação em Administração da Pontifícia Universidade Católica do Paraná no Campus Curitiba. Para coleta de dados elaborou-se um questionário estruturado contendo 20 questões, aplicado no período de dois meses: outubro e novembro de 2007, período em que o mercado financeiro brasileiro encontrava-se com relativa estabilidade. $O$ processo de amostragem foi o não-probabilístico e pode ser caracterizado como sendo por conveniência e adesão. Esses questionários foram aplicados em salas de aulas, junto aos alunos e professores que já realizaram algum tipo de investimento em ativos de renda variável, mediante a aprovação de diversos docentes da referida Instituição de Ensino Superior.

\subsection{Método de Análise}

Para realização deste trabalho foi realizado um levantamento bibliográfico sobre os principais assuntos sobre finanças comportamentais, sendo que as principais fontes de pesquisa constituíramse de periódicos nacionais e internacionais. Os dados foram analisados, utilizando-se como ferramentas estatísticas as análises descritivas, de cluster e discriminante. Para processamento dos dados coletados foi utilizado 0 pacote computacional Statistica for Windows versão 6.0.

Inicialmente, os dados foram analisados valendo-se das estatísticas descritivas, que tem como principal objetivo descrever o comportamento da amostra quanto ao desempenho das variáveis, por meio do uso de medidas de posição tais como a média, distribuições de freqüência e gráficos. Esta análise foi utilizada com o objetivo de estabelecer comparações entre os grupos que participaram da pesquisa.

No segundo momento, foi aplicada a análise de cluster, também conhecida como análise de conglomerados ou de agrupamento. Segundo Hair Junior et al. (2005, p. 384) esta análise pode ser definida como "um grupo de técnicas multivariadas cuja finalidade primária é agregar objetos com base nas características que eles possuem". Da mesma forma, Malhotra (2001, p. 526) define a análise de conglomerados como uma técnica usada para classificar objetos ou casos em grupos relativamente homogêneos chamados conglomerados. De acordo com estes autores, os conglomerados obtidos devem apresentar tanto uma homogeneidade interna (dentro de cada conglomerado), bem como em função da grande heterogeneidade externa (entre conglomerados), se diferenciando dos demais.

Malhotra (2001, p. 528) estabelece as seguintes etapas para aplicação da análise de conglomerados: formulação do problema, onde se define com quais variáveis a aglomeração será 
baseada; a escolha de uma medida de distância, que determina o quão semelhantes ou diferentes serão os grupos formados; a escolha de um processo de aglomeração; a decisão quanto ao número de conglomerados, que exige julgamento por parte do pesquisador; a interpretação e perfilação dos conglomerados e para finalizar, a avaliação quanto à validade do processo de aglomeração.

De uma forma geral, as técnicas de agrupamento ou processos de aglomeração se dividem em 3 grupos de análises: as técnicas hierárquicas, as técnicas de partição (nãohierárquicas) e as técnicas de coberturas. Para análise dos dados deste trabalho foram aplicadas as técnicas de análise hierárquica, sendo utilizada como medida de distância a "distância euclidiana" e como método de aglomeração o ward's method, também denominado método da variância. O objetivo da aplicação desta técnica foi a formação de grupos ou clusters de acordo com as respostas fornecidas pelos entrevistados.

No processo de análise utilizou-se também a técnica de análise discriminante. Segundo Malhotra (2001, p. 482), está "é uma técnica de análise de dados onde a variável dependente é categórica e as variáveis prognosticadoras ou independentes têm natureza intervalar". Para este autor, os objetivos da análise discriminante se dividem em: estabelecer funções discriminantes, ou combinações lineares das variáveis independentes, que melhor discriminem entre as categorias da variável dependente (grupos); verificar se existe diferenças significantes entre os grupos, em termos das variáveis independentes; determinar as variáveis preditoras que mais contribuem com as diferenças entre grupos; enquadrar, ou classificar, os casos em um dos grupos, com base nos valores das variáveis preditoras e avaliar a precisão da classificação.

Neste trabalho, fez-se o uso da técnica de análise discriminante múltipla, dado que variável dependente, definida como os grupos ou clusters formados por meio da Análise de cluster, envolve três ou mais categorias. Segundo Hair Junior et al. (2005, p. 206) a Análise Discriminante encontra ampla aplicação "em situações nas qual o objetivo principal é identificar o grupo a qual um objeto (por exemplo, uma pessoa ou um produto) pertence".

Malhotra (2001, p. 484) estabelece como passos para a realização desta análise a formulação do problema; a estimação dos coeficientes da função; a determinação da significância da função; a interpretação dos resultados; e a validação dos resultados. A técnica de Análise Discriminante foi aplicada como forma de validação dos grupos que foram encontrados a partir da Análise de clusters.

\section{Apresentação e Análise dos Dados}

Para realização da análise descritiva foram distribuídas as respostas dos questionários em quatro categorias distintas: dados pessoais, aspectos financeiros, conhecimentos do mercado financeiro, além dos aspectos comportamentais.

Quanto aos aspectos pessoais dos entrevistados, observa-se predominância do local de residência na cidade de Curitiba. A amostra de discentes apontou uma pequena predominância do sexo masculino, 58\% em relação ao total; sendo este a predominância, com aproximadamente $79 \%$ dos casos, no grupo de docentes. De acordo com a faixa etária, $61 \%$ dos discentes declararam ter entre 21 e 30 anos, no entanto, as faixas etárias de 21 anos até 30 anos, bem como, 31 anos até 40 anos, demonstraram-se predominante na amostra de docentes, 36\% e 39\%, respectivamente. Em cerca de $77 \%$ dos casos, os discentes identificaram-se como solteiros. Quanto ao estado civil dos docentes, verifica-se um predomínio de $39 \%$ de solteiros e $48 \%$ de pessoas casadas.

Considerando os aspectos financeiros, observase que os discentes em sua maioria afirmam que não possuem dependentes financeiramente. Em relação às respostas dos docentes, os números de dependentes indicados apresentam-se muito diversificados, variando de nenhum até quatro ou mais dependentes, contudo, igualmente na amostra de discentes, observa-se predominância de $48 \%$ de pessoas sem dependentes financeiros.

A renda observada predominante dos discentes com $49 \%$ de participação compreende o valor de até $R \$ 1.000,00$, sendo que a faixa salarial de $R \$$ $1.001,00$, até $\mathrm{R} \$ 2.500,00$ apresentou-se como $34 \%$ do total. Com $43 \%$ de participação, a renda salarial dos docentes compreendeu a faixa de $\mathrm{R} \$$ 2.501,00, a $\mathrm{R} \$ 3.500,00$.

Quanto a conhecimentos do mercado financeiro tornou possível conhecer que investimentos em fundos de renda fixa e Bolsa de Valores representam o referencial de rentabilidade mais citado nas duas amostras. No entanto, a caderneta de poupança mostrou-se ainda muito lembrada pelos docentes e discentes. Já quando considerado a experiência em investimentos financeiros, 48\% dos discentes responderem não possuir nenhuma experiência nesta modalidade, sendo que 29\% do total citaram o Certificado de Depósito Bancário (CDB) e a caderneta de poupança. Quanto aos 
docentes, fundos de renda fixa e caderneta de poupança foram às opções mais citadas, $24 \%$ e $42 \%$, respectivamente.

Mesmo com a opção pelos fundos de ações não tendo sido citada de maneira predominante nas duas amostras quanto ao aspecto experiência, analisou-se que $20 \%$ dos discentes afirmaram já ter realizado algum investimento em ações, bem como $55 \%$ do total de docentes. Outro ponto importante a salientar é que $68 \%$ dos discentes que nunca investiram em ações ou fundo de ações afirmaram que poderiam realizar tal investimento em momento oportuno. $\mathrm{Na}$ amostra dos docentes verificou $36 \%$ de incidência da mesma resposta.
No tocante ao conhecimento sobre o mercado acionário, em ambas as amostras verifica-se que grande parcela dos respondentes afirmou não possuir conhecimentos acerca deste mercado, bem como muitos ainda se classificaram como aprendizes. Torna-se necessário enfatizar que mesmos aqueles que declararam já investir em ações ainda não sentem segurança plena para realizar tal investimento e têm muito a aprender sobre este assunto. Os resultados auferidos a partir dos questionamentos anteriormente encontram-se expostos na Figura 2.
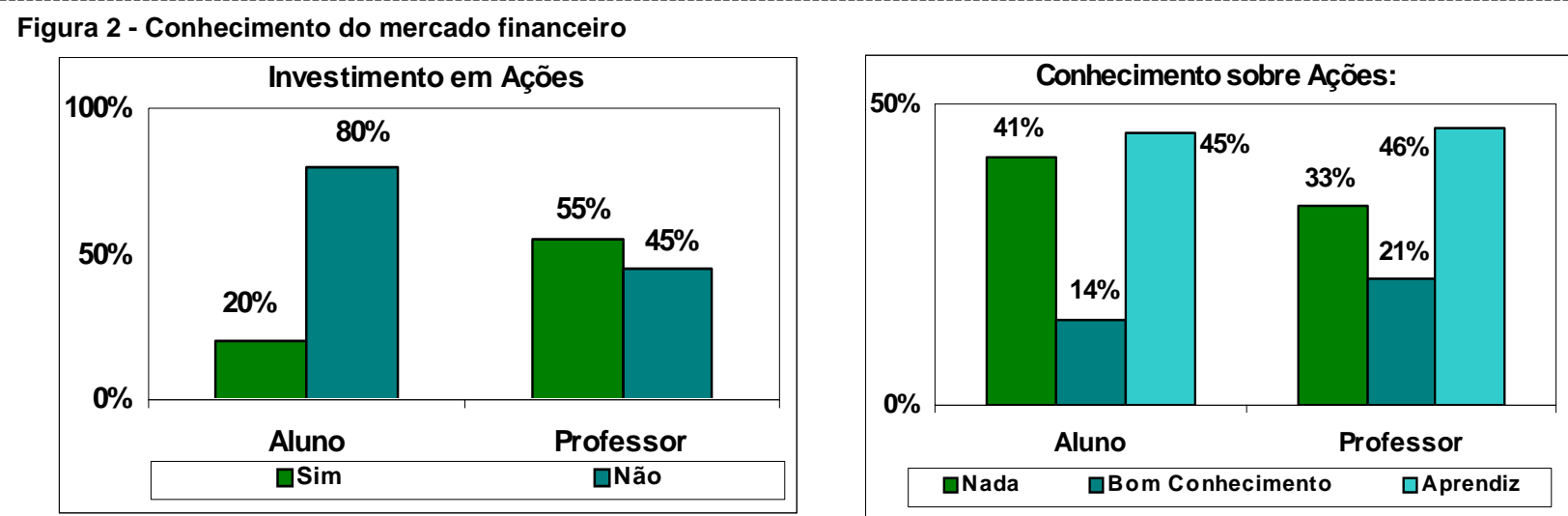

Fonte: os Autores.

Nos aspectos comportamentais analisa-se que a decisão por compra de seguros apresentou-se unânime em ambas as amostras. A imagem da Bolsa de Valores para muitos representa um mercado de risco com caráter especulativo, no entanto, para 36\% das duas amostras, esta representa uma opção de investimento com melhor rentabilidade. Os resultados acerca dos aspectos comportamentais dos respondentes encontram-se expostos na Figura 3.

Figura 3 - Aspectos Comportamentais dos Respondentes
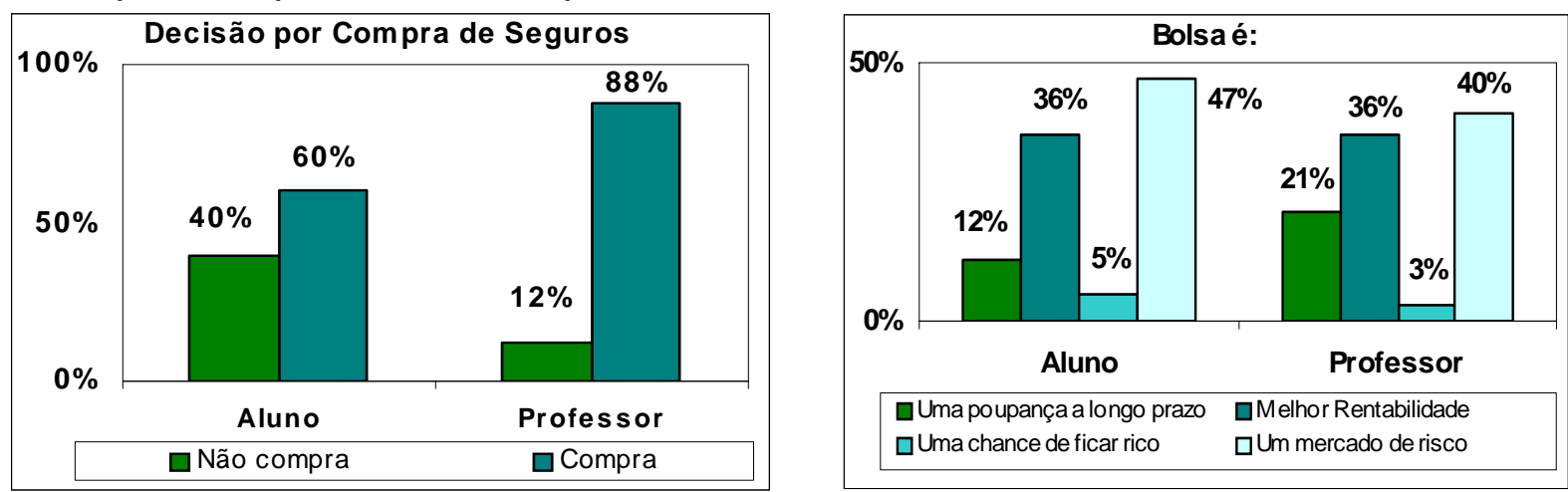

Fonte: Os Autores

Questionando os respondentes quanto a sua atitude caso a Bolsa de Valores "caísse" em dado momento, ambos na totalidade responderam que manteriam a posição das suas carteiras de investimento por dado momento. 
Considerando as respostas quanto ao percentual aceitável de perda, verificou-se que $44 \%$ dos discentes, bem como $46 \%$ dos docentes, aceitariam apenas $5 \%$ de perda máxima dos seus investimentos. Os resultados auferidos para o grau de conhecimento a respeito da Bolsa de Valores encontram-se expressos na Figura 4.

Figura 4 - Grau de Conhecimento Sobre Bolsa de Valores
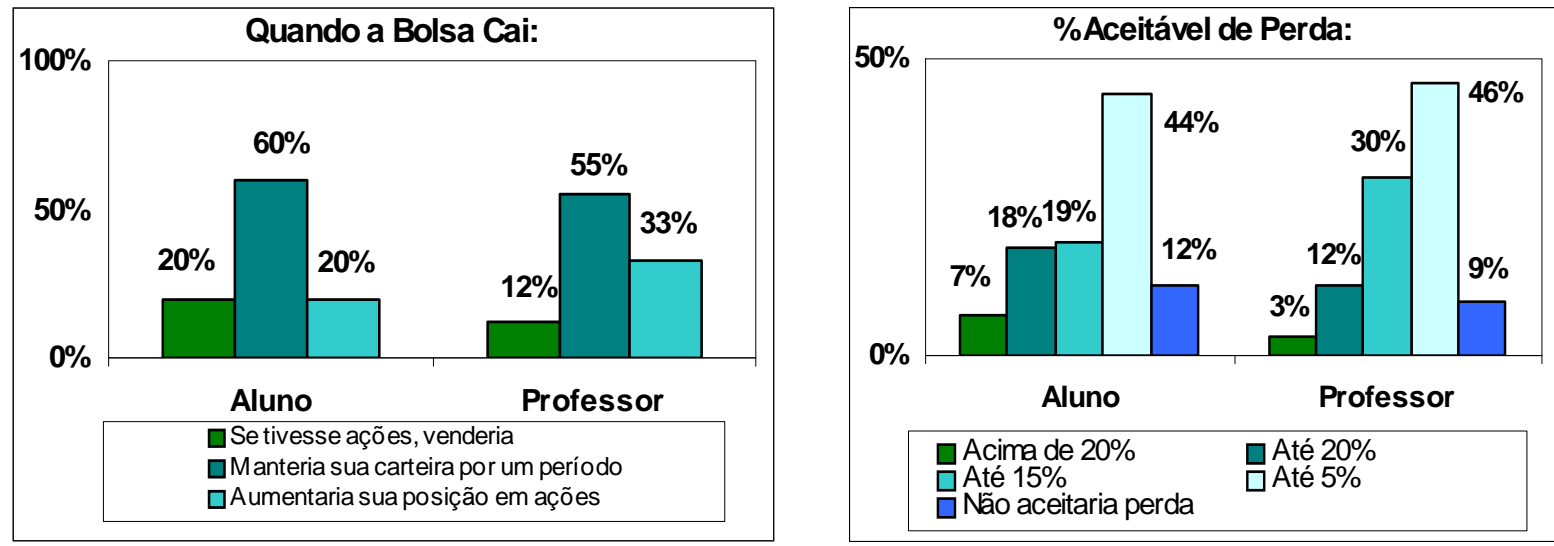

Fonte: Os Autores

Os respondentes mostraram-se relativamente otimistas no longo prazo, sendo que $65 \%$ dos discentes e $70 \%$ dos docentes acreditam em um crescimento moderado do Brasil no ano de 2006.

O perfil quanto ao risco, na amostra de discentes, $45 \%$ classifica-se como conservador, $51 \%$ como moderado e apenas $4 \%$ como agressivo. Já na amostra dos docentes, verificou-se $36 \%$ intitulados como perfil conservador, $61 \%$ como moderado, sendo que 3\% deste total acreditam compor a categoria de agressividade quanto ao risco. Os resultados obtidos para o crescimento da economia e perfil de risco dos respondentes encontram-se na Figura 5.

Figura 5 - Aspectos Comportamentais dos respondentes
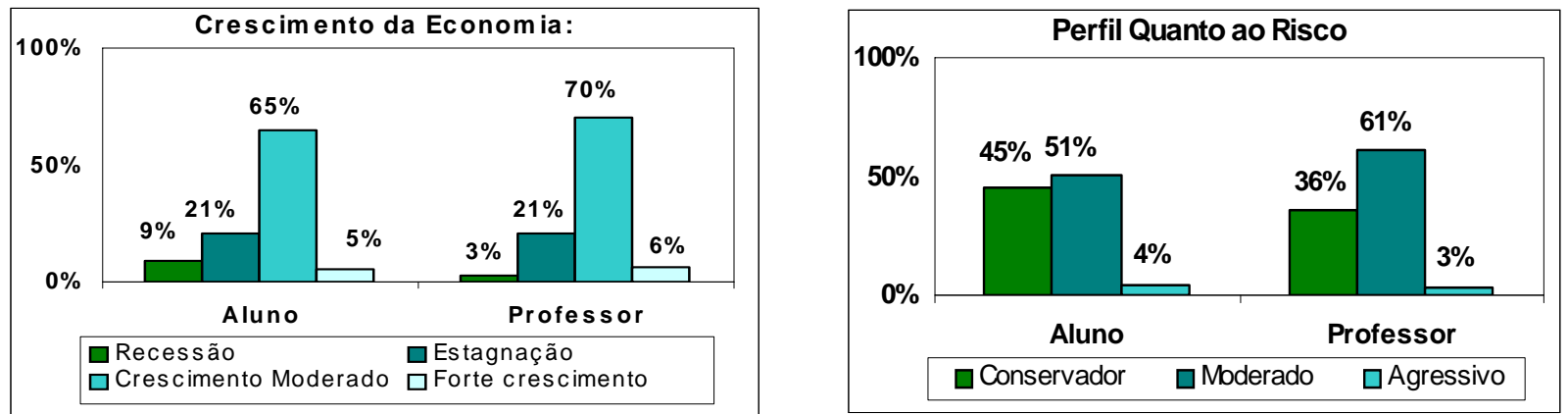

Fonte: Os Autores

De acordo com estes resultados, procurou-se com a aplicação da Análise de Cluster, dividir as duas amostras em grupos distintos, utilizando como variáveis as perguntas formuladas no questionário da pesquisa. Neste processo, algumas variáveis foram desconsideradas do processo devido a elevada significância ( $p>0,05)$, identificadas por meio do teste de hipóteses de Análise de Variância (ANOVA). Estas variáveis foram retiradas por não apresentaram contribuições significativas para formação dos clusters.
Assim, tais variáveis fazem referência principalmente à residência dos entrevistados e ao comportamento em relação à Bolsa de Valores, como percentual de investimento, fonte de informações, objetivos dos investimentos, dentre outras.

Ademais, as variáveis restantes foram analisadas pautando-se na análise hierárquica, utilizando a distância euclidiana e o método de aglomeração ward's method. O resultado desta análise pode ser visualizado no gráfico Dendrograma exposto na Figura 6. 
Figura 6 - Dendograma Apresentando a Classificação dos Clusters

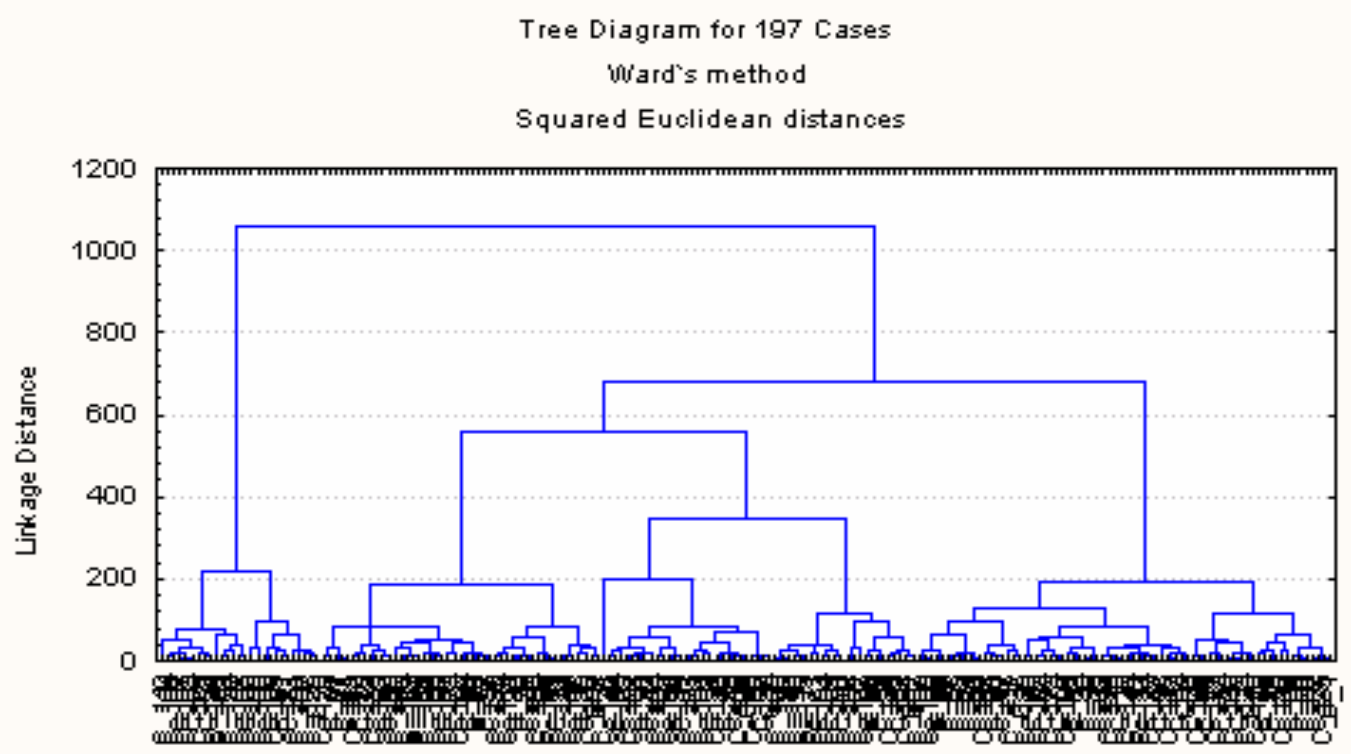

Fonte: Os Autores

Por intermédio da análise do dendograma foram gerados cinco clusters com características distintas, compreendendo a prática e comportamento para as questionário desta pesquisa. A distribuição das amostras de discentes e docentes nos respectivos diversas modalidades investimentos citadas no clusters pode ser verificada na Tabela 1.

\begin{tabular}{|c|c|c|c|c|c|}
\hline $\begin{array}{l}\text { Principais } \\
\text { perguntas } \\
\text { selecionadas }\end{array}$ & $\begin{array}{l}\text { Cluster 1: } \\
\text { Propenso } \\
\text { Investidor } \\
\text { Moderado }\end{array}$ & $\begin{array}{l}\text { Cluster 2: } \\
\text { Propenso } \\
\text { Investidor } \\
\text { Conservador }\end{array}$ & $\begin{array}{l}\text { Cluster 3: } \\
\text { Investidor } \\
\text { Jovem }\end{array}$ & $\begin{array}{l}\text { Cluster 4: } \\
\text { Propensa } \\
\text { Investidora } \\
\text { Conservadora } \\
\end{array}$ & $\begin{array}{l}\text { Cluster 5: } \\
\text { Investidor } \\
\text { Adulto }\end{array}$ \\
\hline Gênero & Masculino & Masculino & Masculino & Feminino & Masculino \\
\hline Estado civil & Solteiro & Solteiro & Solteiro & Solteiro & Casado \\
\hline Idade & 21 a 30 anos & 21 a 40 anos & 21 a 30 anos & 21 a 30 anos & $21 a<50$ anos \\
\hline $\begin{array}{ll}\begin{array}{l}\text { Número } \\
\text { dependentes }\end{array} & \text { de } \\
\end{array}$ & Nenhum & Nenhum & Nenhum & Nenhum & $\begin{array}{c}1-4 \\
\text { dependentes } \\
\end{array}$ \\
\hline Renda mensal & Até $\mathrm{R} \$ 1.000$ & $\begin{array}{l}\text { De } R \$ 1.000 \mathrm{a} \\
\mathrm{R} \$ 2.500\end{array}$ & $\begin{array}{l}\text { De } R \$ 1.000 \mathrm{a} \\
\mathrm{R} \$ 3.500\end{array}$ & $\begin{array}{l}\text { De } R \$ 1.000 \mathrm{a} \\
\mathrm{R} \$ 2.500\end{array}$ & $\begin{array}{l}\text { De } R \$ 2.501 \mathrm{a}< \\
\mathrm{R} \$ 4.000\end{array}$ \\
\hline $\begin{array}{l}\text { Investimentos } \\
\text { realizados em } \\
\text { ações }\end{array}$ & $\begin{array}{l}\text { Não, mas } \\
\text { poderia realizar no } \\
\text { futuro. }\end{array}$ & $\begin{array}{l}\text { Não, mas } \\
\text { poderia realizar no } \\
\text { futuro. }\end{array}$ & $\begin{array}{l}\text { Sim, mas com } \\
\text { receio. }\end{array}$ & $\begin{array}{l}\text { Não, mas } \\
\text { poderia realizar no } \\
\text { futuro. }\end{array}$ & $\begin{array}{l}\text { Sim, mas com } \\
\text { receio. }\end{array}$ \\
\hline $\begin{array}{ll}\text { Referencial } & \text { de } \\
\text { rentabilidade } & \\
\end{array}$ & $\begin{array}{c}\text { Poupança e } \\
\text { fundo de renda fixa }\end{array}$ & $\begin{array}{c}\text { Poupança e } \\
\text { fundo de renda fixa }\end{array}$ & $\begin{array}{cc}\text { Bolsa } & \text { de } \\
\text { Valores e Dólar } & \\
\end{array}$ & Poupança & $\begin{array}{c}\text { Poupança } e \\
\text { fundo de renda fixa }\end{array}$ \\
\hline $\begin{array}{l}\text { Para você, Bolsa } \\
\text { é: }\end{array}$ & $\begin{array}{l}\text { Um mercado de } \\
\text { risco e especulativo }\end{array}$ & $\begin{array}{l}\text { Um mercado de } \\
\text { risco e especulativo }\end{array}$ & $\begin{array}{l}\text { Oportunidade } \\
\text { de } \\
\text { rentabilidade }\end{array}$ & $\begin{array}{l}\text { Um mercado de } \\
\text { risco e especulativo }\end{array}$ & $\begin{array}{l}\text { Oportunidade } \\
\text { de } \\
\text { rentabilidade }\end{array}$ \\
\hline $\begin{array}{l}\text { Quando a Bolsa } \\
\text { cai: }\end{array}$ & \begin{tabular}{lll}
\multicolumn{2}{c}{ Manteria } & sua \\
carteira por & um \\
período & & \\
\end{tabular} & \begin{tabular}{lll}
\multicolumn{2}{c}{ Manteria } & sua \\
carteira por & um \\
período & & \\
\end{tabular} & \begin{tabular}{lll}
\multicolumn{2}{c}{ Manteria } & sua \\
carteira por & um \\
período & & \\
\end{tabular} & \begin{tabular}{lll}
\multicolumn{2}{c}{ Manteria } & sua \\
carteira por & um \\
período & & \\
\end{tabular} & \begin{tabular}{lll}
\multicolumn{2}{c}{ Manteria sua } \\
carteira por um \\
período
\end{tabular} \\
\hline $\begin{array}{lr}\% \text { Aceitável } & \text { de } \\
\text { perda } & \text { em } \\
\text { investimentos } & \\
\end{array}$ & Até $5 \%$ & Até 5\% & Até 5\% & Até $5 \%$ & Até $5 \%$ \\
\hline $\begin{array}{lr}\text { Visão } & \text { de } \\
\text { crescimento } & \text { da } \\
\text { economia } & \text { nos } \\
\text { próximos anos } & \end{array}$ & $\begin{array}{l}\text { Crescimento } \\
\text { Moderado }\end{array}$ & $\begin{array}{l}\text { Crescimento } \\
\text { Moderado }\end{array}$ & $\begin{array}{l}\text { Crescimento } \\
\text { Moderado }\end{array}$ & $\begin{array}{l}\text { Crescimento } \\
\text { Moderado }\end{array}$ & $\begin{array}{l}\text { Crescimento } \\
\text { Moderado }\end{array}$ \\
\hline $\begin{array}{l}\text { Conhecimento do } \\
\text { mercado de ações }\end{array}$ & Aprendiz & $\begin{array}{l}\text { Ausência total } \\
\text { do conhecimento }\end{array}$ & Aprendiz & $\begin{array}{l}\text { Ausência total } \\
\text { do conhecimento }\end{array}$ & Aprendiz \\
\hline $\begin{array}{l}\text { Perfil quanto ao } \\
\text { risco }\end{array}$ & Moderado & Conservador & Moderado & Conservador & Conservador \\
\hline $\begin{array}{lr}\text { Total } & \text { de } \\
\text { participantes } & \text { nos } \\
\text { clusters } & \\
\end{array}$ & 41 & 22 & 49 & 56 & 29 \\
\hline Alunos & $90 \%$ & $91 \%$ & $82 \%$ & $95 \%$ & $48 \%$ \\
\hline Professores & $10 \%$ & $9 \%$ & $18 \%$ & $5 \%$ & $52 \%$ \\
\hline
\end{tabular}

Nota: vale destacar que, em alguns casos, os participantes estão presentes em mais de um cluster.

Fonte: Os Autores 
De acordo com as análises das características individuais de cada cluster realizou-se uma nomenclatura específica e peculiar para cada um destes.

O primeiro cluster foi nomeado como Propenso Investidor Moderado. Neste grupo observou-se a predominância de discentes do gênero masculino, solteiros, idade entre 21 anos até 30 anos, com rendimentos até $R \$ 1.000,00$, sem dependentes financeiros e tendo a caderneta de poupança e fundos de renda fixa como referenciais de rentabilidade. Demonstrou-se igualmente não possuir experiência no mercado financeiro, bem como perfil moderado em relação ao risco. No entanto, o que realmente caracteriza este cluster como Propenso Investidor Moderado consiste na verificação de que mesmo não tendo ainda realizado nenhum investimento em Bolsa de Valores poderia realizá-lo em momento oportuno.

Como Propenso Investidor Conservador, foi nomeado o segundo cluster, compondo esta classificação também de discentes do gênero masculino, solteiros, idade entre 21 anos e 40 anos, com rendimentos de $\mathrm{R} \$ 1.000,00$ até $\mathrm{R} \$$ 2.500,00 predominantemente, sem dependentes financeiros, sendo verificados caderneta de poupança e fundos de renda fixa como referenciais de rentabilidade. Assim, como no cluster anterior, constatou-se que seus integrantes possuem experiência no mercado financeiro, apresentam perfil conservador em relação ao risco, bem como realizariam investimentos em Bolsas de Valores em um momento apropriado e confortável financeiramente.

O terceiro cluster ficou denominado como Investidor Jovem, pois observou-se que 34\% dos entrevistados já realizaram investimentos em Bolsa de Valores, bem como, 53\% mostrou propensão em realizá-lo em momento oportuno. O investidor neste cluster é masculino, solteiro, idade predominante entre 21 anos até 30 anos, renda de $\mathrm{R} \$ 1.000,00$ até $\mathrm{R} \$ 3.500,00$, sem apresentar pessoas que o dependam financeiramente. A Bolsa de Valores é inquestionavelmente sua melhor referência de rentabilidade (73\% do total), demonstrando perfil moderado quanto ao risco.

A maior predominância do sexo feminino ocorreu apenas no quarto cluster, com aproximadamente de $57 \%$ do total. Neste conglomerado constatou-se que a maioria dos entrevistados pode ser classificada como investidor conservador em relação a sua exposição ao risco, desprovidos de experiência no mercado, mas com desejo de investir na Bolsa de Valores em um momento futuro. A poupança foi o investimento mais citado como referência de rentabilidade, $51,8 \%$ do total. Desse modo, intitulou este cluster como Propensa Investidora Conservadora, solteira, idade 21 anos a 30 anos, faixa salarial de $\mathrm{R} \$ 1.000,00$ até $\mathrm{R} \$ 2.500,00$ sem dependentes financeiros, apontando a caderneta de poupança como principal referencial para rentabilidade.

No último cluster verifica-se um perfil bem distinto dos demais. O investidor classificado neste cluster é do sexo masculino, idade predominante entre 31 anos e acima de 50 anos, rendimentos entre $R \$ 2.501,00$ e acima de $R \$$ 4.500,00, apresentando predominância de mais de um dependente financeiro. Os entrevistados neste conglomerado citaram igualmente fundo de Bolsa de Valores e renda fixa como principais referências de rentabilidade, ambos com 34,5\%. Aproximadamente $62 \%$ deste total intitulou-se como conservador em relação ao risco, no entanto, $65 \%$ declarou já ter investido em Bolsa de Valores, desta maneira, este cluster ficou caracterizado como o do Investidor Adulto.

Torna-se importante enfatizar que no quinto e último cluster houve uma predominância do número de docentes em relação aos discentes, aproximadamente $52 \%$ do total. Contundo, mesmo com um elevado percentual não existem evidências suficientes para afirmar que a amostra de docentes pertence a um cluster exclusivo, a conclusão mais provável é que o perfil do professor investidor assemelha-se muito em relação ao do aluno investidor.

Para confirmação dos clusters encontrados, foi aplicada a técnica de análise de discriminante. Como variável dependente utilizou-se os clusters formados por meio da análise de agrupamentos. As variáveis independentes foram representadas pelas perguntas constantes no questionário desta pesquisa, sendo selecionadas apenas as variáveis que apresentaram uma significância $(p<0,05)$. Os resultados da análise de discriminante podem ser visualizados a partir da Figura 7. 
Figura 7 - Variações Totais das Funções F1 e F2

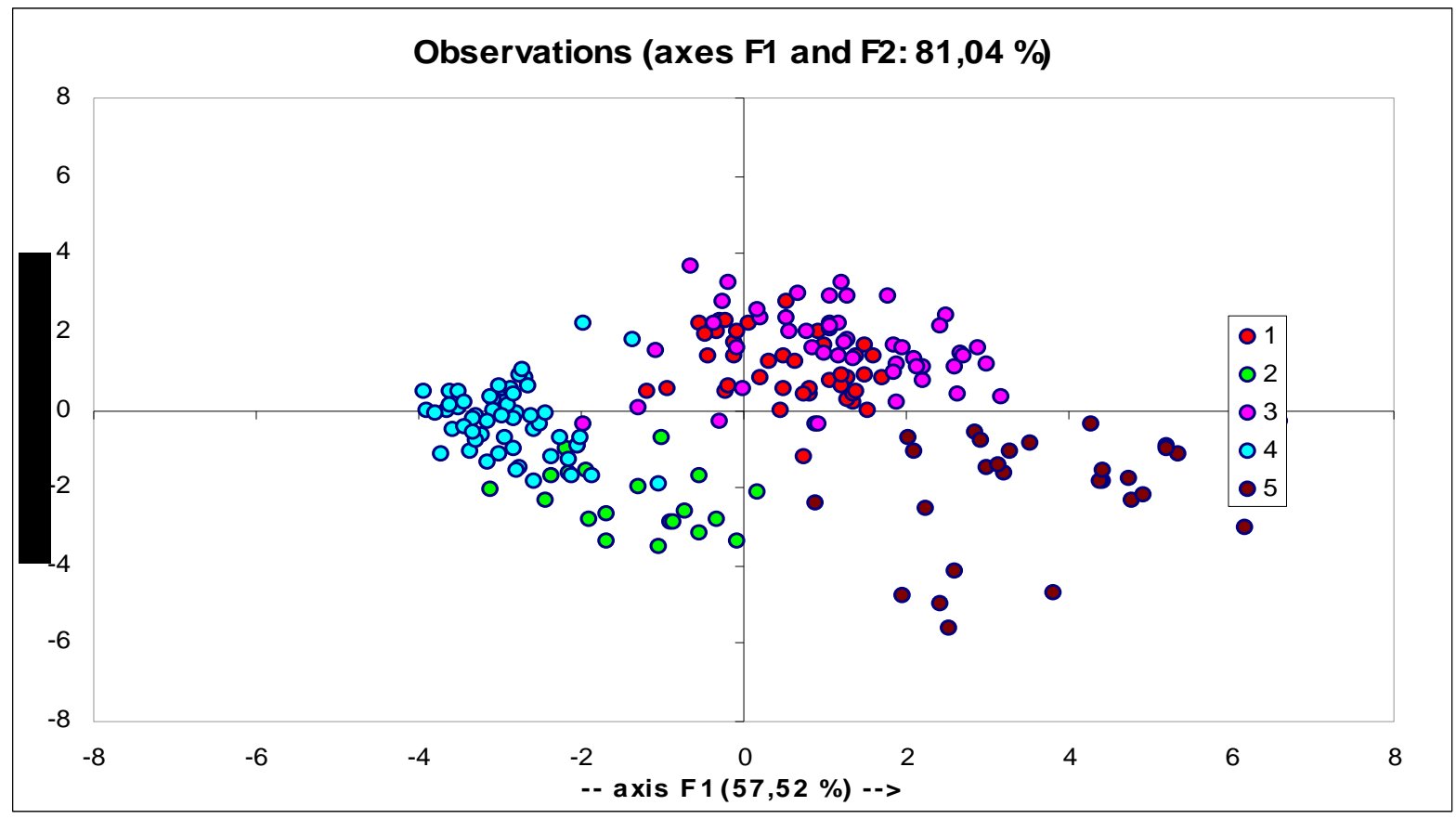

Fonte: Os Autores

Foram obtidas quatro funções discriminantes distintas, contudo, as funções que apresentaram maior capacidade para agrupamentos corretos foram aquelas denotadas como F1 e F2, com valores de $57,52 \%$ e $23,52 \%$, respectivamente. Neste caso, obteve-se $81,04 \%$ de explicação da variância total, com essas duas variáveis comprovando que as classificações dos grupos foram realizadas corretamente. Torna-se importante mencionar que se obteve um valor de 0,016 para o lambda de Wilks, demonstrando assim que as médias dos grupos são consideravelmente diferentes.

Quanto à mensuração do erro, este compreendeu apenas $3,55 \%$ dos casos, abrangendo apenas sete observações agrupadas de maneira atípica às demais, sendo assim, a precisão da classificação (razão de sucesso) é de 96,45\%. Logo, torna-se possível afirmar que o resultado desta pesquisa compreende a identificação de cinco clusters distintos conforme comentários realizados anteriormente.

\section{Considerações Finais, Limitações e Recomendações}

Alguns conceitos contemplados na teoria de Finanças comportamentais vieram ser confirmados por meio dos resultados deste estudo empírico, tais como, o conceito de aversão à perda defendida por Kahneman e Tverski (1979).
De acordo com as análises realizadas, verificouse que do total das amostras estudadas, $12 \%$ não aceitariam definitivamente perdas em seus investimentos, bem como $45 \%$ deste mesmo total externou aceitar uma perda máxima de até $5 \%$ do seu capital investido.

Outro ponto confirmado pela teoria de Finanças comportamentais foi o medo do arrependimento. Constatou-se pelo presente que $59,4 \%$ de ambas as amostras manteria a posição de suas ações por um período caso a Bolsa de Valores apresentasse queda em um momento específico.

Quanto à classificação dos cinco grupos distintos obtidos por meio das técnicas de análises de cluster e discriminante, uma importante constatação realizada baseou-se no fato de que com exceção dos clusters Investidor Jovem e Investidor Adulto, os quais apontaram integrantes que já realizaram investimentos em Bolsa de Valores, verificou-se que a grande maioria que nunca realizou tal investimento demonstrou prédisposição em realizá-lo num momento oportuno.

Alguns fatores tais como a falta de conhecimento a respeito do mercado acionário, bem como a insuficiência de renda, podem representar alguns dos fatores para um baixo número de investidores nesta modalidade de investimento.

A principal contribuição desta pesquisa diz respeito ao fornecimento de elementos que possa entender o para o entendimento sobre o perfil 
comportamental do investidor e do propenso investidor, algo ainda explorado de forma incipiente na literatura nacional.

Nesse contexto, há um longo percurso a ser seguido pelas finanças comportamentais, principalmente por ter-se um argumento marcado por um conjunto de teorias, que não são compatíveis e ainda não possuem significância suficiente para substituir o modelo atual de Finanças.

No Brasil, por exemplo, os estudos relacionados a Finanças comportamentais encontram-se em um estágio considerado muito incipiente. Contudo, a discussão acerca deste tema encontra-se muito longe de ser resolvida ou esgotada, sendo assim, existe um amplo campo para realização de valiosos estudos teóricos e empíricos que podem ser realizados sobre este tema, em especial o desenvolvimento de modelos matemáticos confiáveis que venham a sustentar a sua teoria.

Cabe ressaltar algumas limitações desta pesquisa: a primeira delas diz respeito ao conjunto de indivíduos que participaram da pesquisa. Em função da quantidade de participantes, isso pode não refletir sobre a composição da população brasileira.

Um outro aspecto a ser levado em consideração refere-se à inexistência ou desconhecimento de estudos similares no Brasil, isso impede que se possam apoiar as argumentações aqui inseridas, fazendo contraposições ou confirmações acerca de achados que se consideram essenciais para ratificar os resultados encontrados nessa pesquisa.

O fato da coleta dos dados ter se baseado num processo de amostragem não probabilística, faz com que os seus resultados não possam ser generalizados para toda população. Os resultados auferidos devem ficar circunscritos ao fenômeno pesquisado.

Destaca-se ainda o fato de que o entendimento dos erros de cognição, os quais moldam o comportamento dos agentes econômicos, frente à tomada de decisões, constitui-se numa matéria essencial para a explicação de fenômenos financeiros, que visam orientar a composição de políticas públicas ou privadas, tão essenciais na explicação de fenômenos financeiros.

As questões explicitadas anteriormente fornecem um aparato para o desenvolvimento de outras pesquisas. Deste modo, para a elaboração de pesquisas futuras, sugere-se a replicação deste mesmo estudo considerando desta vez um processo de amostragem probabilístico;

\section{Referências}

BAKER, H. K., NOFSINGER, J. R. Psychological biases of investors. Financial Services Review, v. 11, n. 2, p. 97-116, 2002.

BERNSTEIN, P. L. Desafio aos deuses: a fascinante história do risco. Campus: Rio de Janeiro, 1997.

Carducci, B.; Wong, A. Type a and risk taking in everyday money matters. Journal of Business and Psychology, v. 12, n. 3, p. 355-359, 1998.

CHURCHILL JUNIOR, Gilbert A. A marketing research: methodological foundations. 7. ed. Orlando: Dryden Press, 1998.

DHAR, R.; ZHU, N. Up close and personal: investor sophistication and the disposition effect.

Management Science, v. 52, n. 5, p. 726-740, 2006.

FAMA, E. F. FRENCH, K. R. Permanent and temporary components of stock prices. Journal of Political Economy, v. 98, p. 247-272, 1988.

GRABLE, J. Financial risk tolerance and additional factors that affect risk taking in everyday money matters. Journal of Business Psychology, v. 14, n. 4, p. 625-630, 2000.

HAFELD, M. TORRES, F. L. Finanças comportamentais: aplicações no contexto brasileiro. Revista de Administração de Empresas, v. 41, n. 2, abr/jun, 2001.

HAIR JUNIOR et al. Análise multivariada de dados. 5. ed. Porto Alegre: Bookman, 2005.

HAUGEN, R. A. Beast on Wall Street: how stock volatility devours our wealth. Upper Saddle River, NJ: Prentice Hall, 1999.

KAHNEMAN, D. TVERSKI, A. Prospect theory; an analysis of decision under risk. Econometrica, $v$. 47, n. 2, p. 263-291, 1979.

TVERSKY, A.; KAHNEMAN, D. The framing of decisions and the psychology of choice, Science, 211, 450-458, 1981.

LAMPENIUS, N.; ZICKAR, M. J. Development and validation of a model and measure of financial risktaking. Journal of Behavioral Finance, v. 6, n. 3, p. 129-143, Sep., 2005.

LIMA, M. V. Um estudo sobre finanças comportamentais. Revista de Administração de empresas. v. 2, n. 1, jan/jun, 2003.

MACEDO. J. S. Teoria do prospecto: uma investigação utilizando simulação de investimentos. Disponível em: < http://teses.eps.ufsc.br/Resumo.asp?5266> Acesso: 12 jun. 2005. 
MALHOTRA, N. K. Pesquisa de marketing. Uma orientação aplicada. 3. ed. Porto Alegre: Bookman, 2001.

MARCON. R. et al. Análise de aversão à perda em finanças comportamentais e na teoria de psicanalítica. Disponível em:

<http://www.investsul.com.br/textos_academicos/Fi nan\%E7as\%20Comportamentais\%20-

\%20CLADEA\%20-.doc> Acesso em: 20 jul. 2005.

ODEAN, T. Are investors reluctant to realize their losses? Journal of Finance, v. 53, n. 5, p. 17751798, 1998.

SIMON, R. A behavioral model of rational choice. Quarterly Journal of Economics, v. 12, n. 6, p. 99-118, 1976.

THALER, R. H. The end of behavioral finance. Association for Investment Management and Research, November/December, 1999.

TVERSKI, A. Investment decisions are filtered through mental biases - hard-wired predispositions - that color and frequently cloud perceptions of events and opportunities. Dow Jones

Management, v. II, n. 6, p. 21-28. Leaders in Finance, 1995. 